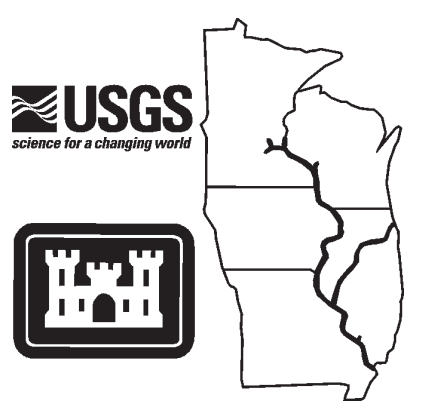

Long Term Resource Monitoring Program

Technical Report 2006-T001

\title{
Long Term Resource Monitoring Program Water Quality Component Review
}

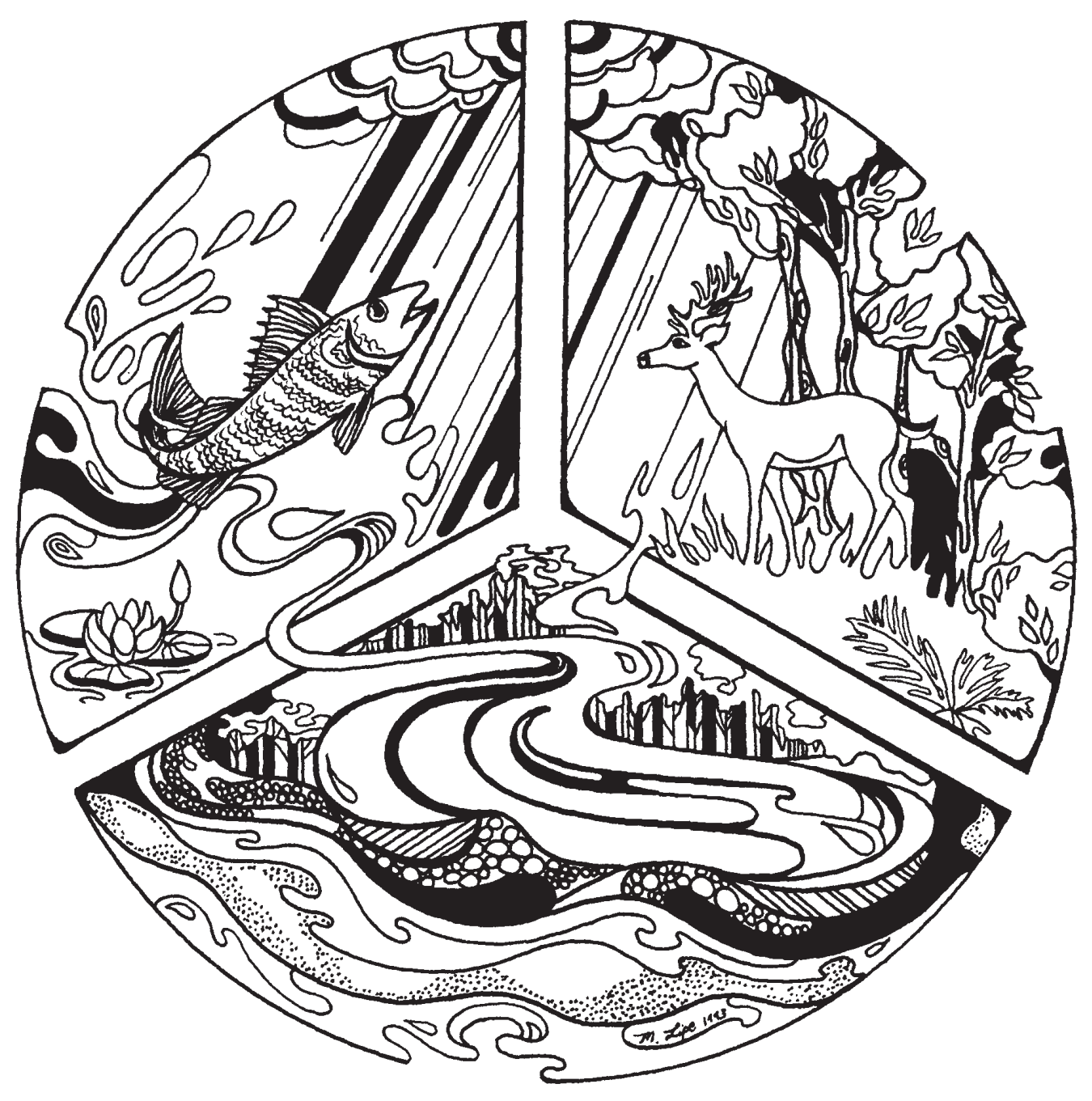

June 2006 


\title{
Long Term Resource Monitoring Program Technical Reports
} provide Long Term Resource Monitoring Program partners with scientific and technical support.

All reports in this series receive anonymous peer review.

\author{
Cover graphic by Mi Ae Lipe-Butterbrodt
}

Mention of trade names or commercial products does not constitute endorsement or recommendation for use by the U.S. Department of the Interior, U.S. Geological Survey.

4 Printed on recycled paper 


\title{
Long Term Resource Monitoring Program Water Quality Component Review
}

\author{
by \\ David M. Soballe and Jeffrey N. Houser
}

Report submitted to

U.S. Army Corps of Engineers District, Rock Island

Clock Tower Building

PO Box 2004

Rock Island, Illinois 61204-2004

June 2006

\author{
U.S. Geological Survey \\ Upper Midwest Environmental Sciences Center \\ 2630 Fanta Reed Road \\ La Crosse, Wisconsin 54603
}


Suggested citation:

Soballe, D. M, and J. N. Houser. 2006. Long Term Resource Monitoring Program Water Quality Component Review. U.S. Geological Survey, Upper Midwest Environmental Sciences Center, La Crosse, Wisconsin. LTRMP 2006-T001. 9 pp.

Additional copies of this report may be obtained from the National Technical Information Service, 5285 Port Royal Road, Springfield, VA 22161 (1-800-553-6847 or 703-487-4650). Also available to registered users from the Defense Technical Information Center, Attn: Help Desk, 8725 Kingman Road, Suite 0944, Fort Belvoir, VA 22060-6218 (1-800-225-3842 or 703-767-9050). 


\section{Contents}

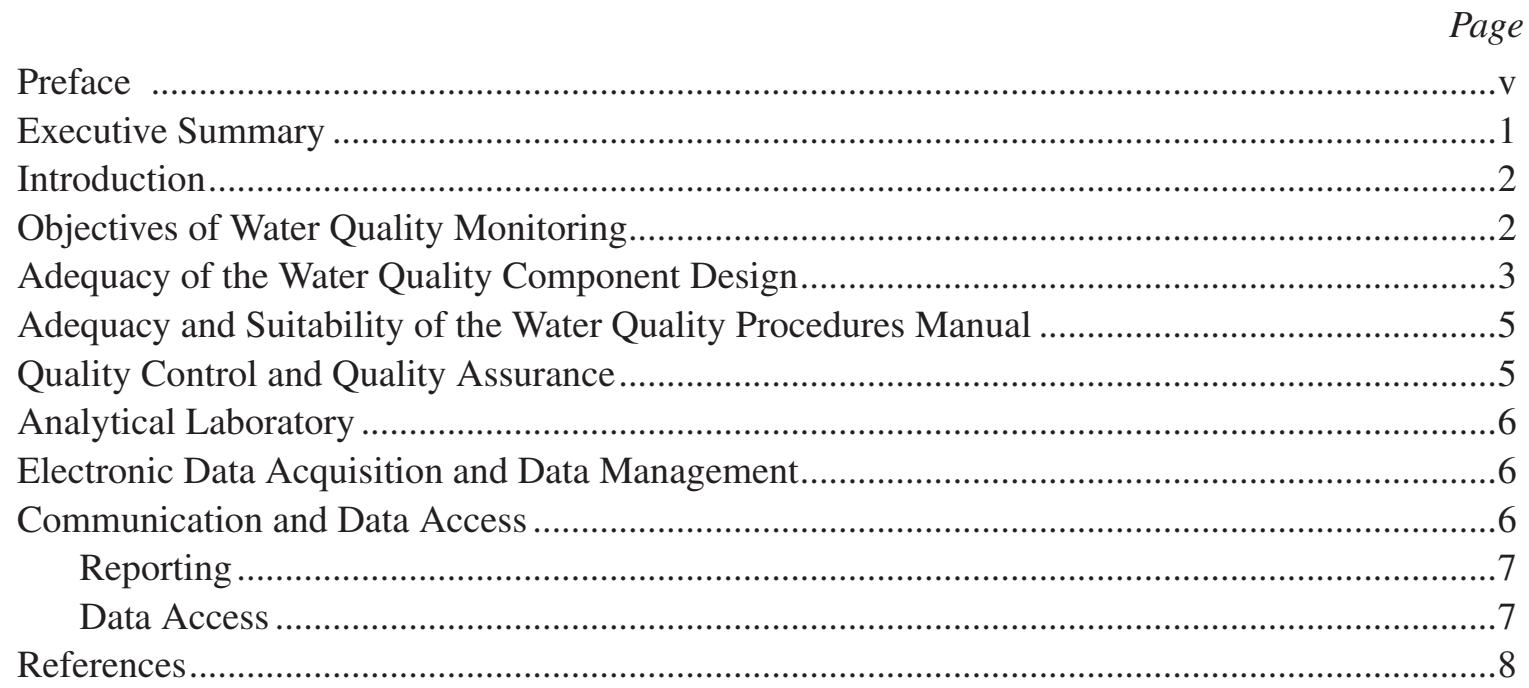




\section{Preface}

The Long Term Resource Monitoring Program (LTRMP) was authorized under the Water Resources Development Act of 1986 (Public Law 99-662) as an element of the U.S. Army Corps of Engineers' Environmental Management Program. The LTRMP is being implemented by the Upper Midwest Environmental Sciences Center, a U.S. Geological Survey science center, in cooperation with the five Upper Mississippi River System (UMRS) States of Illinois, Iowa, Minnesota, Missouri, and Wisconsin. The U.S. Army Corps of Engineers provides guidance and has overall Program responsibility. The mode of operation and respective roles of the agencies are outlined in a 1988 Memorandum of Agreement.

The UMRS encompasses the commercially navigable reaches of the Upper Mississippi River, as well as the Illinois River and navigable portions of the Kaskaskia, Black, St. Croix, and Minnesota Rivers. Congress has declared the UMRS to be both a nationally significant ecosystem and a nationally significant commercial navigation system. The mission of the LTRMP is to provide decision makers with information for maintaining the UMRS as a sustainable large river ecosystem given its multiuse character. The long-term goals of the Program are to understand the system, determine resource trends and effects, develop management alternatives, manage information, and develop useful products.

This report supports Task 2.2.3.7 as specified in Goal 2, Evaluate and Refine Experimental Design, of the LTRMP Operating Plan (U.S. Fish and Wildlife Service 1993). This report was developed with funding provided by the LTRMP. 


\title{
Long Term Resource Monitoring Program Water Quality Component Review
}

\author{
by
}

David M. Soballe and Jeffrey N. Houser

\section{Executive Summary}

A review of the Long Term Resource Monitoring Program (LTRMP) water quality component was conducted in May-June 2002 and considered seven aspects of the program: (1) objectives of water quality monitoring relative to LTRMP objectives, (2) potential of the current sampling design to meet those objectives, (3) adequacy and suitability of the water quality procedures manual, (4) adequacy and efficiency of procedures for quality assurance and quality control in data collection and laboratory analyses, (5) operations of the analytical laboratory, (6) recent implementation of electronic data acquisition, and (7) communications and data access. The review was conducted by a panel of five external experts who reviewed program documents and then met at the Upper Midwest Environmental Sciences Center from 3-7 June 2002.

The panel found that the objectives of water quality monitoring program are tightly interconnected and one element cannot be neglected without negatively affecting the others. The panel emphasized the need for increased analysis of existing data. It is only by analyzing the data and submitting the findings to external peer review that the final step in quality assurance is achieved, the adequacy of the design is fully tested, redundancies are revealed, and the actual value of the collected data is clearly shown and documented. The panel also emphasized that distribution of data and communication of findings are critical functions of the LTRMP.

The panel found that the documentation of LTRMP water quality monitoring procedures (Soballe and Fischer 2004) is excellent, describing scientifically sound methods in appropriate detail to interpret the data collected under the program, to ensure standardization among sampling teams, and to duplicate the sampling program in other locations with other personnel. The panel agreed that the current combination of fixed site and stratified random sampling is well suited to examination of conditions at scales of whole pools or entire study reaches across multiple years. The panel found that data acquisition and data management employed by the LTRMP water quality component are exceptional, and that the quality assurance protocols are excellent, exceeding the levels used in many similar programs. This was not a water quality lab audit and the panel recommended that the laboratory continue its participation in such activities as the Standard Reference Sample Program of the USGS.

The panel noted that LTRMP derived information is not being used to the extent possible by resource managers in the development and evaluation of resource 
management alternatives, and offered a number of suggestions. Closer liaison with management agencies may be needed (i.e. direct involvement of UMESC staff in HREP planning and review, and center participation in other project planning activities) to improve use of LTRMP information and expertise. The USGS is a partner in, not a contractor to, the Environmental Management Program (EMP). As the lead science agency in the EMP partnership, a primary role for USGS is to ensure that sound science drives management and decision-making in EMP projects.

\section{Introduction}

The Long Term Resource Monitoring Program (LTRMP) and the Upper Mississippi River System (UMRS) that it addresses are complex. The full scope and intent of this program, its constraints, and the intricacies of its design and operation are not easily or quickly grasped. Thus, a meaningful review required the reviewers to be, or become, familiar with the river system and with the design and operations of the LTRMP and water quality component. Because the review covered broad areas, no single reviewer was expected to have expertise in all areas addressed. The review was conducted by a panel of five external experts (Table) who reviewed program documents and then met at the Upper Midwest Environmental Sciences Center from 3-7 June 2002.

Table. Review panel members and affiliations

Dr. John Elder - U.S. Geological Survey, Middleton, Wisconsin

Prof. Fred Bryan - U.S. Geological Survey, Louisiana Cooperative Fish and Wildlife Research Unit, Louisiana State University, Baton Rouge, Louisiana

John Sullivan - Wisconsin Department of Natural Resources, La Crosse, Wisconsin

David Bierl - U.S. Army Corps of Engineers - Rock Island, Illinois

Kent Johnson - Metropolitan Council, Environmental Services, St. Paul, Minnesota

\section{Objectives of Water Quality Monitoring}

In this review, the objectives of the LTRMP water quality component were considered relative to the following LTRMP programmatic goals: the requirements for developing scientifically sound information on river resources, the relationship of the LTRMP to regional and national environmental issues and programs, the needs for monitoring and research activities within USGS and other agencies (leveraging, efficiency, and redundancy), and the long-term outlook for support of limnological monitoring within the LTRMP.

The overall goals of the LTRMP are defined in the operating plan (U.S. Fish and Wildlife Service 1993) as follows: (1) develop a better understanding of the ecology of the UMRS and its resource problems, (2) monitor resource change, (3) develop alternatives to better manage the Upper Mississippi River System, and (4) provide for the proper management of LTRMP information. The panel found that the goals in the LTRMP Operating Plan are interconnected and one element cannot be neglected for an extended period (i.e., several years) without negatively affecting the others. In particular, the panel reaffirmed the urgent need for the LTRMP, as a whole, to place increasing emphasis on analysis of existing data and on new investigations that explore and establish the linkages among biotic components and the physical-chemical template in the system. Investigations of this sort are essential to address Goal 1 (better understand the ecology of the system) and Goal 3 (evaluate management alternatives) of the LTRMP Operating Plan. These investigations are also fundamental to evaluating the effectiveness of on-going work under Goal 2 (monitor resource change). For example, the connection between water quality conditions at various temporal and spatial scales, and the distribution and abundance of river biota (probably at larger scales) must be explored more intensely to understand the role of physical and 
chemical factors in the ecology of the system, to evaluate the potential effects of management actions that alter these physical-chemical features, and to assess the adequacy or appropriateness of the water quality monitoring data collected by the LTRMP components. In addition, there are major biotic components of the system (i.e., microbial communities and plankton) that are ignored under the existing design of the monitoring program, but which may drive, or warn of, basic system changes. Explicit review comments cited the lack of detailed analyses that would allow a more quantitative assessment of design efficacy and efficiency.

The panel pointed out that the monitoring program cannot just document changes in resources, it should also provide early warning of serious threat to those resources. This is not possible without adequate ecological understanding. Important biotic changes in the system (e.g., the invasion of zebra mussels) should generate a detectable signal in the monitoring data. In fact, the LTRMP water quality data does suggest an influence of zebra mussels on dissolved oxygen and planktonic chlorophyll levels at selected locations, but without focused investigations, those possible linkages cannot be confirmed.

\section{Adequacy of the Water Quality Component Design}

The review of the water quality component design was intended to address three general questions. How well does the water quality component design support the overall goals of LTRMP? What deficiencies exist that must be corrected? What improvements can be implemented within the constraints of available resources to increase efficiency and information yield?

The basic concept for water quality monitoring within the LTRMP is that the abundance and community composition of the system's biota depends upon combinations of physical, chemical, and biological features in the river that vary across a wide range of temporal and spatial scales. In the context of the LTRMP goals, water quality monitoring is intended to help identify and understand those physical and chemical features that are most significant to long-term biotic integrity and sustainability of the system, track changes in the critical features that influence biota, provide information to guide science-based management of physical-chemical aspects of the system, and obtain, process, and maintain information in a reliable, rapid, and cost-effective manner.

A major purpose of the LTRMP is to detect the ecological effects of major management activities (i.e., the multiple phase habitat rehabilitation activity in Pool 8) and the panel agreed that monitoring under the LTRMP must be able to detect effects of a meaningful magnitude in a timely manner and with suitable levels of confidence. For example, the effects of multiple habitat rehabilitation projects (e.g., Pool 8) should be detectible in the LTRMP data if these project(s) have had substantial influence at the entire pool (or reach) scale. However, analyses to address such effects specifically have not been conducted. Because the present monitoring design targets broad-scale effects, it is unlikely that routine monitoring that does not specifically focus on local areas where projects are implemented will consistently or adequately indicate the near-field (i.e., $<1 \mathrm{~km}$ ) or short-term (i.e., $<$ annual) influences of such projects.

The panel was briefed on the history of the LTRMP and its sampling design. It was pointed out that translating the general goals of the LTRMP into a specific design for the water quality component has required compromise, professional judgment, and extended interactions with program partners. The panel agreed that the combination of fixed site and stratified random sampling now included in the design seems well suited to examination of conditions at scales of whole pools or entire study reaches across multiple years. The existing design, however, was intended to be combined with focused investigations of specific processes and mechanisms, thus phenomena at spatial scales smaller than an individual study reach and time scales less than a season or year have not been addressed. LTRMP staffing and budget limitations have generally not allowed sufficient time for analysis, interpretation, and reporting 
of data within the water quality component and among biotic components of the LTRMP. This deficiency was noted as critical because it is not possible to determine adequacy or redundancy until the data are used to answer specific questions. Statistical explorations showing similarities and differences among sampling areas and times may prove useful, but more importantly, the interconnections between the biotic measurements of LTRMP and the physical-chemical environment must be explored and demonstrated. These explorations are thus far in their infancy. Changes in the existing monitoring program suggested by further analysis of collected data should be driven by specific information needs and done carefully to avoid compromising the existing period of record.

The review team was unanimous in its finding that episodic phenomena (e.g., as may be driven by synoptic weather conditions, or water level management) that may exhibit only short-term, local effects on water quality may also have profound and lasting influences on river biota at the annual and multiannual scales. The team concluded that sacrificing some information at the annual-full reach scale may be justified if this would allow critical information to be obtained at finer scales. For example, information on the episodic development of low-oxygen conditions at critical points in time or space may be needed to accurately assess the design or potential benefit of habitat projects intended to promote an important species of fish or invertebrate. Before water quality sampling effort is reallocated, however, detailed examination of the existing data obtained for the program and close coordination with the field teams and resource managers are required to develop a strategy that preserves as much information as possible from the existing design and ensures that new approaches are productive. The LTRMP staff has proposed inclusion of intensive focused studies of important processes several times since 1993, but few of these proposals have been funded.

Navigation is perhaps the largest single human activity within the mainstem river-floodplain. It seems, therefore, that the
LTRMP design should be suitable to detect the ecological impact of the navigation system and changes in the operation of that system. The LTRMP water quality data were used extensively in the modeling exercises performed as part of the U.S. Army Corps of Engineers navigation feasibility studies. However, the primary target scale of LTRMP measurements (whole-pool, annual, multiyear time frame) and the lack of integrated analyses across components at smaller spatial and temporal scales has made it difficult for LTRMP to address either the shorter-term effects of navigation or the benefits of management actions taken to remediate these effects.

The LTRMP design (across all components) should also provide early warning of major ecological changes in the system as they begin to emerge. In that regard, it seems advisable for the program to direct some effort toward meaningful ecological indicators. In water quality, phytoplankton abundance and assemblage composition may provide one such indicator (see point \#3 below). Additional work is needed, however, to determine what aspects of phytoplankton abundance and assemblage composition are appropriate indicators.

In light of the conclusions on the sampling design, the review team developed a number of alternatives (not exhaustive) for evaluation to help address these issues:

1. Consider the development of index sites or geographic areas that capture a substantial portion of the water quality information (variance and interrelations) obtained in a full stratified random sampling (SRS) episode, but at substantially less effort. Monitoring of these index sites or areas on a rotating annual or seasonal basis could be substituted for a quarterly SRS episode while other intensive work is conducted by the field teams. Alternatively, on a rotating, multiyear basis, this subset of index sites or areas could be sampled at intervals more frequently than the quarterly design and substitute for one or more quarterly SRS sampling episodes. The time freed up by use of rotating index sites could also be used for analysis of existing data. The 
effect of any change in sampling structure must be carefully evaluated before any change is made. Subsequent to this review, an initial analysis of the water quality for the purpose of identifying "index" sites was conducted and was unable to identify a small number of sites representative of any given pool.

2. Consider periodic (e.g., once every 4 years) specialized focus studies. While continuing with the mandated long-term monitoring, the periodic specialized studies should be preceded by trend analyses of all historical data.

3. Explore more avenues to obtain selected analysis of the warehoused phytoplankton samples. These samples, collected at a subset of monitoring locations over nearly 10 years, should be an extremely valuable resource. Because the phytoplankton community is tied to the water quality of the system and is integral to providing an early warning for changes or disturbances in the system, a carefully selected subset of samples should be analyzed to determine the condition of these archived samples and provide some assessment of temporal and spatial variations in the community. Part of this effort should be aimed at documenting the normal pattern of variation (seasonal succession and longitudinal zonation) against which changes can be detected.

Diatom indices relating diatom community composition to the chemical environment are well established for some freshwater systems and may offer strong potential for use in the UMRS with limited effort toward developing new techniques or indices. Exploratory analyses of the archived phytoplankton samples were initiated in FY 2005. Linkages to the U.S. Environmental Protection Agency Great Rivers Environmental Monitoring and Assessment Program and other initiatives on large river indicators should be considered.

\section{Adequacy and Suitability of the Water Quality Procedures Manual}

The review panel found overall that documentation of LTRMP water quality monitoring procedures is excellent, describing scientifically sound methods at appropriate detail to interpret the data collected under the program, to ensure standardization among sampling teams, and to duplicate the sampling program in other locations with other personnel. The panel members provided a substantial number of suggestions on the procedures manual that were incorporated into the final version (Soballe and Fischer 2004). The panel suggested that the utility of future editions of the procedures manual might be improved by separating the detailed description of each method from the rationale behind the measurements. The LTRMP staff has considered producing a series of single-sheet quick-guides for those procedures for which detailed instructions are most commonly needed in the field. Substantial excerpts from the procedures manual are included in the online help in the electronic data sheet software.

\section{Quality Control and Quality Assurance}

Quality control and quality assurance (QA/QC) procedures in the water quality component of the LTRMP are designed to quantify the reliability of the water-quality data and allow identification and correction of specific sources of error or variance. Various recommendations or requirements for QA/QC have been published (USEPA 1974, APHA 1998) and the recommendations of standard methods (APHA 1998), with minor modifications, are the basis for QA/QC procedures in the water quality component.

The panel found, at their level of expertise, the QA/QC protocols in use by the LTRMP water quality component to be excellent, exceeding the levels used in many similar programs. The panel recommended adding biannual blind sample testing for $\mathrm{pH}$ and specific conductance to the field protocols and encouraged continued participation of the laboratory in the Standard Reference Sample program of the National Water Quality Laboratory. The panel also agreed that the potential for obtaining formal laboratory and program certification (e.g. National Environmental Laboratory Accreditation Program) based on existing practices should be investigated, as this certification would formally recognize the high level of work being performed 
in LTRMP water quality and increase the national credibility of the program.

\section{Analytical Laboratory}

The water quality laboratory at the Upper Midwest Environmental Sciences Center (UMESC) makes over 80,000 analytical determinations per year in support of the LTRMP water quality component. The laboratory uses a high level of automation and adheres to methods that are fully documented and widely accepted (e.g., Standard Methods; APHA 1998). Levels of precision and accuracy are intended to be within the standards for normal laboratory practice and are checked with quality assurance and quality control procedures that adhere to established norms. This component review was not a laboratory audit. The panel recommended that the laboratory continue to participate in such activities as the Standard Reference Sample Program of the USGS. The laboratory participated in the Standard Reference Sample Program in Spring 2002 (received a 4.0 out of 4.0 rating), Fall 2004 (received a 3.8 out of 4.0 rating), and Spring 2005 (LTRMP lab results were all within $2 \%$ of official results).

\section{Electronic Data Acquisition and Data Management}

Beginning in 1993, the use of barcodes for automated tracking of samples and data was implemented (Chapter 7.14, Soballe and Fischer 2004). Each item of data in the LTRMP database is permanently linked to the bar code on its original data sheet and the sample bar codes are used to track samples through the analytical laboratory. Thus the bar codes provide an automated method for tracking data and samples through the entire processing system. The bar codes serve to streamline error tracking and correcting, streamline sample processing and tracking, and improve data handling, as well as sample accounting and accountability. In 1995, the water quality component of the LTRMP began using electronic data capture and transmission as the primary method for obtaining and transferring selected field information and custody records to the analytical laboratory from the LTRMP field stations. However, paper data sheets and a separate data entry contractor remained the primary method for field data acquisition. The use of paper data sheets and data entry contractor introduced a significant number of errors in the data (about 1-5 errors per 100 data sheets) which required unacceptable amounts of staff time to detect, research, and correct. The delivery of data to end users was delayed while errors were being found and corrected by senior science staff. In response, an electronic data sheet system was implemented by the LTRMP water quality component in 2001. This electronic approach obtains readings directly from the field instruments and carefully cross-checks user inputs as they are entered into the data sheet to ensure that complete and accurate information is obtained in the field. The system also includes electronic transfer of all field data and custody records to the analytical laboratory. This approach eliminates the use of a data entry contractor, but more importantly, the results from the first year of operation (about 6000 data sheets processed) show that it virtually eliminates data errors.

The review panel found that data acquisition and data management employed by the LTRMP water quality component are exceptional. Electronic data acquisition and transmission was a major advance that enhances the quality of the data and has lead to dramatic shortening of the time required to provide the data to end users. The new procedures provide substantial improvements in the physical protection and integrity of the collected data over the previous, paper-based, approach. Maintaining existing paper archives for the field data is essential, but the generation of paper archives into the future should be revisited.

\section{Communication and Data Access}

The panel emphasized that distribution of data and communication of findings are critical functions of the LTRMP. Only by analyzing the data for scientific publication and submitting the findings to external peer review is the final step in quality assurance achieved, the adequacy of the design fully tested (revealing redundancies), and the actual value of the collected data 
clearly shown and documented. Analysis and publication have been chronic weak points in the LTRMP for a host of legitimate reasons. However, the review panel most strongly encourages the program managers to allocate a larger share of the available resources to this endeavor. The program has reached a level of maturity that warrants this shift in emphasis.

Significant improvements related to the distribution of data and information generated by LTRMP are still possible and recommended. The panel strongly encourages the water quality component to continue progressing on methods with the goal of data distribution within 1 year of collection. All laboratory analyses of 2004 water quality samples were completed by 30 March 2005 and data were available to the public by 15 June 2005.

The panel noted that LTRMP derived information is not being used to the extent possible by resource managers in the development and evaluation of resource management alternatives. Major users of LTRMP water quality data (e.g., regulators) come from outside the group of river biologists, engineers, and refuge managers that are considered the core constituency of the LTRMP. The review panel is puzzled as to why this core constituency does not make greater use of this invaluable resource, and has a number of suggestions to offer.

Closer liaison with management agencies may be needed to improve use of LTRMP information and expertise (i.e., direct involvement of the USGS Upper Midwest Environmental Sciences Center (UMESC) staff in Habitat Rehabilitation and Enhancement Project planning and review, and UMESC participation in other project planning activities) . The USGS is a partner in, not a contractor to, the Environmental Management Program (EMP). As the lead science agency in the EMP partnership, a primary role for USGS is to ensure that sound science drives management and decision-making in EMP projects. To the extent practicable, this increase in science inputs to the EMP should be based upon communication, cooperation, and collaboration among UMESC scientists and their counterparts in the EMP partner agencies.

\section{Reporting}

The reporting of the LTRMP water quality data takes several forms. The entire data set is available to the public (http://www.umesc. usgs.gov/data_library/water_quality/water1_ query.shtml) so that specific analyses may be conducted. The data set is complex, however, because of its broad scope in space and time (many years, six study reaches, four seasons, and six strata) and some time must be invested in learning its structure and content before conducting analyses. To make the data more accessible to managers and the public, web browsers that present summary data graphically for use by scientists, managers, and the general public are under development (see next section). A broad summary of the data from $1993-2002$ is available (Houser 2005); summary reports of the earlier years of the program (1993-1996) have also been produced (e.g. Soballe et al. 2002a-d); and presentations based on LTRMP data are regularly made at scientific and river management conferences and meetings (e.g., Houser et al. 2004, Soballe et al. 2004). A comprehensive list of all LTRMP reports can be found at http://www.umesc.usgs.gov/reports_ publications/ltrmp_rep_list.html.

\section{Data Access}

The review panel strongly encouraged the UMESC data management group to modify the existing user interfaces to improve access to the LTRMP data. The LTRMP data browser and the documentation it provides with each data retrieval are extremely useful, especially to more advanced users who need access to raw data. However, other avenues need to be pursued. The graphical user interfaces (GUIs) provided by the stand alone Data Visualization Tool and similar web based graphical browsers under development at UMESC provide an extremely effective entry point into the LTRMP data for both internal and external users. The panel recommended that such interfaces be further developed. The Water Quality Fixed Site Graphical Browser is nearly completed for pools 8 and 13 and the Open River and will be ready for review by the end of FY 2005; Pools 4 and 26 and La Grange 
Pool are scheduled to be completed in FY 2006. A similar graphical browser for the Stratified Random Sampling data is proposed for FY 2006. This Web-based interface is similar to that being offered on the web by USGS Water Resources Division for giving access to river discharge data. In developing new tools for data access, input from various potential users of the LTRMP data should be solicited.

Minor modifications to the existing database browser would likewise be helpful. One modification suggested by the panel, and accomplished in 2004, was to include a header line that allows "comma delimited" retrievals from the browser to be imported directly into a spreadsheet (e.g., Microsoft Excel) with the columns already labeled. In addition, the concept of "canned" retrievals producing a data set consisting of the most commonly requested variables should be considered. Such preprogrammed procedures would allow quick and easy access to the most commonly requested information. Interaction with the data user community (e.g., UMRCC water quality tech section and LTRMP field teams) is essential in developing these "canned" retrievals.

\section{References}

APHA (American Public Health Association). 1998. Standard methods for the examination of water and watewater. $20^{\text {th }}$ edition. American Public Health Association, Washington, D.C.

Houser, J.N., J.T. Rogala, B.R. Gray, J. R. Fischer and B. L. Johnson. 2004. Using long-term monitoring data to understand spatial and temporal variability in the Upper Mississippi River System. Ecological Society of America 89th Annual Meeting. Portland, Oregon. August 1-6.

Houser, J. N., editor. 2005. Multiyear synthesis of limnological data from 1993 to 2001 for the Long Term Resource Monitoring Program. U.S. Geological Survey, Upper Midwest Environment Sciences Center, La Crosse, Wisconsin, March 2005. LTRMP Technical Report 2005-T003. 59 pp. (NTIS PB2005-105228)
Soballe, D. M., J. R. Fischer, L. A. Hodge-Richardson, and T. L. Clemment. 2002a. Limnological monitoring on the Upper Mississippi River System, 1993-1996: Long Term Resource Monitoring Program Onalaska Field Station. U.S. Geological Survey, Upper Midwest Environmental Sciences Center, La Crosse, Wisconsin, October 2002. LTRMP 2002-P003. 20 pp. + Appendixes A-F. (NTIS \#PB2003-101578)

Soballe, D. M., D. E. Gould, S. A. Gritters, R. D. Gent, and M. J. Steuck. 2002b. Limnological monitoring on the Upper Mississippi River System, 1993-1996: Long Term Resource Monitoring Program Bellevue Field Station. U.S. Geological Survey, Upper Midwest Environmental Sciences Center, La Crosse, Wisconsin, October 2002. LTRMP 2002-P004. 16 pp. + Appendixes A-F. (NTIS PB2003-101579)

Soballe, D. M., E. Ratcliff, B. Kerans, and T. Mihuc. 2002c. Limnological monitoring on the Upper Mississippi River System, 1993-1996: Long Term Resource Monitoring Program Pool 26 Field Station. U.S. Geological Survey, Upper Midwest Environmental Sciences Center, La Crosse, Wisconsin, October 2002. LTRMP 2002-P002. 18 pp. + Appendixes A-F. (NTIS PB2003-101577)

Soballe, D. M., R. H. Wright, and S. W. Stenzel. 2002d. Limnological monitoring on the Upper Mississippi River System, 1993-1996: Long Term Resource Monitoring Program Havana Field Station. U.S. Geological Survey, Upper Midwest Environmental Sciences Center, Onalaska, Wisconsin, November 2002. LTRMP 2002-P005. 16 pp. + Appendixes A-F. (NTIS PB2003-101576)

Soballe, D. M., and J. R. Fischer. 2004. Long Term Resource Monitoring Program Procedures: Water quality monitoring. U.S. Geological Survey, Upper Midwest Environmental Sciences Center, La Crosse, Wisconsin, March 2004. Technical Report LTRMP 2004-T002-1 (Ref. 95-P002-5). 73 pp. + Appendixes A-J.

Soballe, D.M., D.M. Wasley, and R.H. Coupe. 2004. Effects of flood timing and spatial distribution on nitrate export from the upper 
Mississippi basin. Mississippi River Research Consortium 36th Annual Meeting. April 1-2. La Crosse, Wisconsin.

USEPA (U.S. Environmental Protection Agency). 1974. Methods for chemical analysis of water and wastes. EPA-625/6-74-003.

U.S. Fish and Wildlife Service. 1993. Operating Plan for the Upper Mississippi River System Long Term Resource Monitoring Program. Environmental Management Technical Center, Onalaska, Wisconsin, Revised September 1993. EMTC 91-P002R. 179 pp. (NTIS \#PB94-160199) 


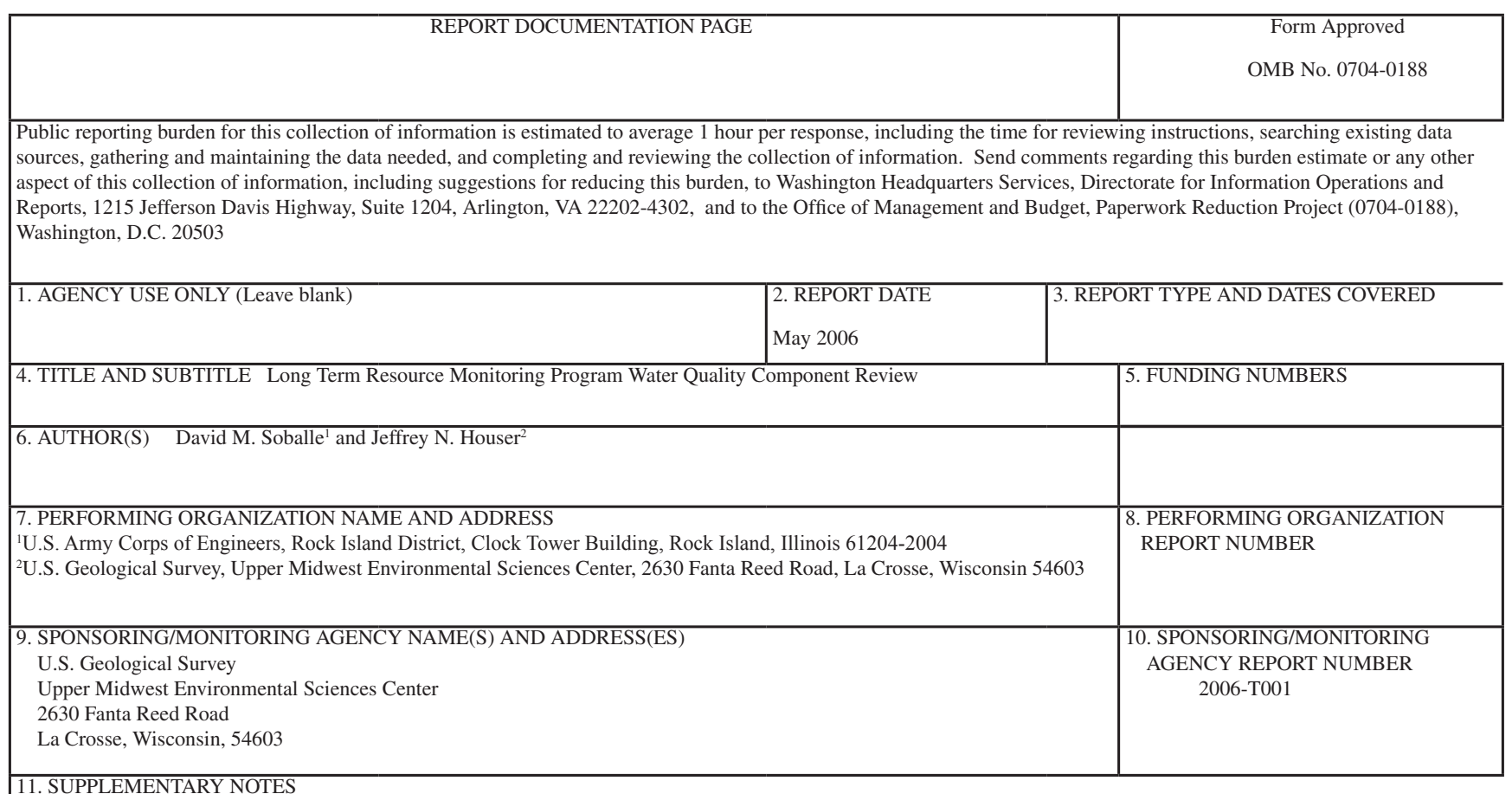

11. SUPPLEMENTARY NOTES

12a. DISTRIBUTION/AVAILABILITY STATEMENT

12b. DISTRIBUTION CODE

Release unlimited. Available from National Technical Information Service, 5285 Port Royal Road, Springfield, VA 22161 (1-

800-553-6847 or 703-487-4650). Also available to registered users from the Defense Technical Information Center, Attn: Help

Desk, 8725 Kingman Road, Suite 0944, Fort Belvoir, VA 22060-6218 (1-800-225-3842 or 703-767-9050).

13. ABSTRACT (Maximum 200 words)

A review of the Long Term Resource Monitoring Program water quality component was conducted in May-June 2002 and considered seven aspects of the program. The review was conducted by a panel of five external experts who reviewed program documents and then met at the Upper Midwest Environmental Sciences Center on 3-7 June 2002 .

\begin{tabular}{|c|c|c|c|}
\hline \multicolumn{3}{|c|}{$\begin{array}{l}\text { 14. SUBJECT TERMS } \\
\text { Adequacy, data manaagement, design, procedure, quality assurance, quality control, water quality }\end{array}$} & \multirow[t]{2}{*}{$\begin{array}{l}\text { 15. NUMBER OF PAGES } \\
9 \text { pp. . }\end{array}$} \\
\hline & & & \\
\hline $\begin{array}{l}\text { 17. SECURITY CLASSIFICATION } \\
\text { OF REPORT }\end{array}$ & $\begin{array}{l}\text { 18. SECURITY CLASSIFICATION } \\
\text { OF THIS PAGE }\end{array}$ & $\begin{array}{l}\text { 19. SECURITY CLASSIFICATION } \\
\text { OF ABSTRACT }\end{array}$ & 20. LIMITATION OF ABSTRACT \\
\hline Unclassified & Unclassified & Unclassified & \\
\hline
\end{tabular}


The Long Term Resource Monitoring Program (LTRMP) for the Upper Mississippi River System was authorized under the Water Resources Development Act of 1986 as an element of the Environmental Management Program. The mission of the LTRMP is to provide river managers with information for maintaining the Upper Mississippi River System as a sustainable large river ecosystem given its multiple-use character. The LTRMP is a cooperative effort by the U.S. Geological Survey, the U.S. Army Corps of Engineers, and the States of Illinois, Iowa, Minnesota, Missouri, and Wisconsin.

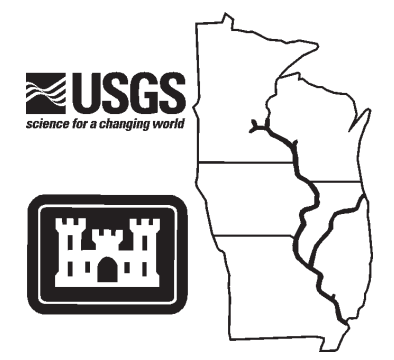

